\title{
Stepwise bioprocess for exopolysaccharide production using potato starch as carbon source
}

\author{
Shashi Kant Bhatia • Narinder Kumar • \\ Ravi Kant Bhatia
}

Received: 14 November 2014/ Accepted: 15 December 2014/Published online: 23 December 2014

(C) The Author(s) 2014. This article is published with open access at Springerlink.com

\begin{abstract}
Xanthan gum is a biopolymer produced by Xanthomonas sp. XC6. In this study, xanthan gum is produced from potato starch using a stepwise bioprocess design. Potato starch is hydrolyzed using Bacillus sp. having amylase activity and $30.2 \mathrm{~g} / \mathrm{L}$ reducing sugar was released, while Xanthomonas sp. XC6 can release only $14.5 \mathrm{~g} / \mathrm{L}$. Bacillus sp. hydrolyzed potato starch extract was further used as a carbon source for xanthan gum biosynthesis using Xanthomonas sp. XC6. Yeast extract acts as the best nitrogen source, and $10.0 \mathrm{~g} / \mathrm{L}$ xanthan gum was recovered. Downstreaming process after stepwise bioprocess resulted in $17.4 \mathrm{~g} / \mathrm{L}$ xanthan gum production, which is 2.8 times higher as compared to single step process.
\end{abstract}

Keywords Biopolymer - Biosynthesis - Downstreaming process - Xanthan gum

\section{Introduction}

Biopolymer is a type of polymer which is produced by living organisms; it contains monomeric units which are covalently bonded to form larger structures (Nwodo et al.

Electronic supplementary material The online version of this article (doi:10.1007/s13205-014-0273-2) contains supplementary material, which is available to authorized users.

S. K. Bhatia - N. Kumar

Department of Biotechnology, Indian Institute of Education,

Ghanahatti, Shimla 171011, India

S. K. Bhatia $(\bowtie) \cdot$ R. K. Bhatia

Department of Biotechnology, Himachal Pradesh University,

Shimla 171005, India

e-mail: shashibiotechhpu@gmail.com
2012). The exopolysaccharide (EPS) is a biopolymer which is composed of high molecular weight polymers made up of sugar residues, and responsible for the architecture and morphology of the matrix in which cells live and serve as a potential energy reserve (Sayyed et al. 2012). Exopolysaccharides of microbial origin have immense potential to be used in food and pharma industry (Gong et al. 2009; Fanga et al. 2013). Xanthan gum is the extracellular polysaccharide produced by Xanthomonas sp. and commercially accepted (Ghazal et al. 2011; Oliveira et al. 2013). It is a heteropolysaccharide and consists of glucose, mannose, and glucuronic in 2:2:1 proportion (Gilani et al. 2011). Bacterium xanthan gum is an attractive alternative for the replacement of traditional gums obtained from plants and marine algae by chemical extraction process (Freitas et al. 2011). Because of its special rheological properties, xanthan gum is used in pharmaceuticals, paper, paint, food, cosmetics, and textile industries due to its high viscosity at low concentrations; pseudo plasticity; and insensitivity to a wide range of temperature and $\mathrm{pH}$ (Gilbert et al. 2013; Patel and Prajapati 2013). In large-scale production of xanthan gum, glucose is considered as a suitable substrate with high production and yield (Zhang and Chen 2010). However, the increasing market demand suggests that glucose may no longer be economically feasible as a raw material, and in order to reduce the costs of raw material for xanthan gum production low cost carbon sources were recommended. There are a number of research studies devoted to identifying a suitable substrate with low costs (Mudoi et al. 2013). Several methods have been developed to increase the yield and properties of xanthan gum using various carbon sources (Silva et al. 2009). The objective of this work is to increase the production of xanthan gum and to find an alternate of glucose as carbon source. In this study, Bacillus sp. is used in the 
saccharification of starch as it is a well established organism and has been used to develop a number of bioprocesses (Patel et al. 2012; Sangkharak and Prasertsan 2013). Bacillus sp. is regarded generally as safe (GRAS) by the Food and Drug Administration. Fermented broth obtained after starch hydrolysis by Bacillus sp. was further used as a carbon source for xanthan gum production using Xanthomonas sp. XC6.

\section{Materials and methods}

Chemicals

All the media components were obtained from Hi-Media (Mumbai, India) and other chemicals were procured from Merck (India).

Microorganism and culture conditions

The infected fruit and leaf from citrus plants showing canker symptom were collected from Shimla, Himachal Pradesh for the isolation of Xanthomonas sp. Isolation was carried out in glucose/yeast/calcium carbonate agar (GYCA) medium (Freitas et al. 2011). The necrotic lesions from leaves and fruits were dissected and surface sterilized in $70 \%$ alcohol. The infected samples were then suspended in a small test tube containing $3 \mathrm{~mL}$ saline and incubated at $30{ }^{\circ} \mathrm{C}$ for $24 \mathrm{~h}$, after that the bacterial suspension were serially diluted in $9 \mathrm{~mL}$ sterile distilled water. Then $0.1 \mathrm{~mL}$ of the diluted bacterial cell suspension was poured into sterilized petri plates containing GYCA medium and incubated for $30{ }^{\circ} \mathrm{C}$ for $72 \mathrm{~h}$. Wild type isolates were selected by choosing yellow, viscous, and convex colony having a diameter of $4 \mathrm{~mm}$. Isolated strains were screened for their xanthan gum production potential. Selected strain was identified by using phenotypic and biochemical characteristics, i.e. morphology, motility, starch, gelatin hydrolysis, and carbohydrate utilization (glucose, fructose, sucrose, maltose, and glycerol) tests. For $16 \mathrm{~s}$ rRNA analysis, genomic DNA was isolated from the bacterial isolates and used as template for PCR. PCR was performed using MycyclerTM (Bio-Rad, USA). The sequence data was checked by BLAST analysis and phylogentic tree was constructed using NCBI (phylip programme). Other strain Bacillus sp. was received from Microbial Type Culture Collection and Gene Bank (IMTECH).

Xanthan gum estimation

Biomass and xanthan gum estimation were performed after withdrawing the sample, for biomass estimation $5 \mathrm{~mL}$ sample was centrifuged at $12,000 \mathrm{rpm}$ for $10 \mathrm{~min}$, then supernatant is decanted and cell pellet is dried in hot air oven at $100{ }^{\circ} \mathrm{C}$ and then weighed. Xanthan gum was extracted from the supernatant using $95 \%$ ethanol for precipitation. The precipitates were separated by centrifugation at $10,000 \mathrm{rpm}$ for $15 \mathrm{~min}$ and dried at $60^{\circ} \mathrm{C}$ and weighed (Meng et al. 2010).

Optimization of cultural conditions

\section{Carbon source}

Different carbon (starch, maltose, glucose, and sucrose) sources were tested for biomass and xanthan gum production by Xanthomonas sp. XC6 at $30{ }^{\circ} \mathrm{C}$ for $120 \mathrm{~h}$. Samples were withdrawn at $24 \mathrm{~h}$ intervals and analyzed for xanthan gum production.

\section{Starch hydrolysis and saccharification}

Isolated bacteria Xanthomonas sp. XC6 can utilize maltose as a carbon source for biomass and xanthan gum production, so potato starch can be used as a cheaper substrate for xanthan gum production. Potato tubers were washed with distilled water to remove dirt, peeled manually and boiled. Boiled potatoes were crushed, mixed with adequate amount of water, filtered through a Teflon cloth, and autoclaved at $121{ }^{\circ} \mathrm{C}$. Saccharification of the potato starch extract was carried out using Xanthomonas sp. XC6 and Bacillus sp. Potato extract containing g/L, $\mathrm{Na}_{2} \mathrm{HPO}_{4} \cdot 12 \mathrm{H}_{2} \mathrm{O}, 2.5 \mathrm{~g}$; $\mathrm{K}_{2} \mathrm{HPO}_{4}, 2.0 \mathrm{~g} ; \mathrm{MgSO}_{4} \cdot 7 \mathrm{H}_{2} \mathrm{O}, 1.0 \mathrm{~g} ; \mathrm{FeSO}_{4} \cdot 7 \mathrm{H}_{2} \mathrm{O}, 0.1 \mathrm{~g}$; and $\mathrm{CaCl}_{2} \cdot 2 \mathrm{H}_{2} \mathrm{O}, 0.6$ and yeast extract $5.0 \mathrm{~g}$ was used as medium. Xanthomonas sp. and Bacillus sp. preculture were inoculated separately in $50 \mathrm{ml}$ medium containing in Erlenmeyer conical flask, and saccharification was carried out at $37{ }^{\circ} \mathrm{C}$ for $96 \mathrm{~h}$. Samples were withdrawn and analyzed for total reducing sugar release using the DNS method (Rajesh et al. 2013).

\section{Xanthan gum production using Xanthomonas sp}

Bacillus sp. scarified potato extract was centrifuged at $15,000 \mathrm{rpm}$ for $15 \mathrm{~min}$ to remove the cell and further subjected for xanthan gum production. The hydrolyzed potato starch extract was used as carbon source and inoculated with the preculture of Xanthomonas sp. and incubated at $37{ }^{\circ} \mathrm{C}$ and further cultural condition optimization was performed.

\section{Effect of nitrogen source and temperature}

Fermented broth obtained after hydrolysis of potato starch by Bacillus sp. was used as sole carbon source, and various 
commercially available nitrogen sources (peptone, yeast extract, beef extract, and malt extract at $1 \%$ ) were checked out to increase the production of xanthan gum. Effect of temperature was also studied by varying it from 20 to $45^{\circ} \mathrm{C}$. After optimization of cultural condition, xanthan gum production at $1 \mathrm{~L}$ performed using fermented broth of Bacillus sp. and reducing sugar content profile was studied under optimized condition up to $120 \mathrm{~h}$.

\section{Xanthan gum production at bench scale}

Under the optimized cultural condition, stepwise fermentation (SF) and simultaneous saccharification and fermentation study were performed at $1 \mathrm{~L}$ scale. In stepwise fermentation, Bacillus sp. was used to hydrolyze potato starch extract and saccharified broth containing $30.2 \mathrm{~g} / \mathrm{L}$ reducing sugar was further incubated at $30{ }^{\circ} \mathrm{C}$ for $72 \mathrm{~h}$ under shaking condition with Xanthomonas sp. XC6 for Xanthan gum production. In simultaneous saccharification and fermentation (SSF), inoculation of potato extract containing optimized medium components directly with preculture of Xanthomonas sp. XC6 was also performed for xanthan gum production under optimized condition. Exopolysaccharide extraction was performed and FTIR analysis was done.

\section{Fourier-transformed infrared spectroscopy (FTIR)}

Xanthan gum was extracted from fermented broth as mentioned above. Samples of purified EPS were prepared for FTIR analysis. One $\mathrm{mg}$ of the purified EPS was used in analysis by using salt discs. A mixture made by adding $1 \mathrm{mg}$ of EPS samples to $300 \mathrm{mg}$ of pure dried $\mathrm{KBr}$ followed by pressing into the disc, the whole FTIR spectrum was analyzed at $400-4,200 \mathrm{~cm}^{-1}$ using Shimadzu FTIR 8300 Spectrophotometer (Shimadzu, Tokyo, Japan).

\section{Results}

Isolation

Totally seven isolates were isolated using GYCA medium and characterized for xanthan gum production. Isolate XC6 showed maximum $(2.4 \mathrm{~g} / \mathrm{L})$ xanthan gum production with $5.5 \mathrm{~g} / \mathrm{L}$ biomass production. Bacterial isolate $\mathrm{XC} 1$ and $\mathrm{XC} 4$ showed good biomass production, but low production of xanthan gum was recorded. Isolates XC2, XC5 and XC7 showed little biomass production as well as xanthan gum production (Fig. 1). Bacterial isolate having higher xanthan gum production potential is identified as Xanthomonas sp. XC6 on the basis of biochemical tests (Table. S1) and confirmed by performing $16 \mathrm{~s}$ rRNA (Figure S1). $16 \mathrm{~s}$

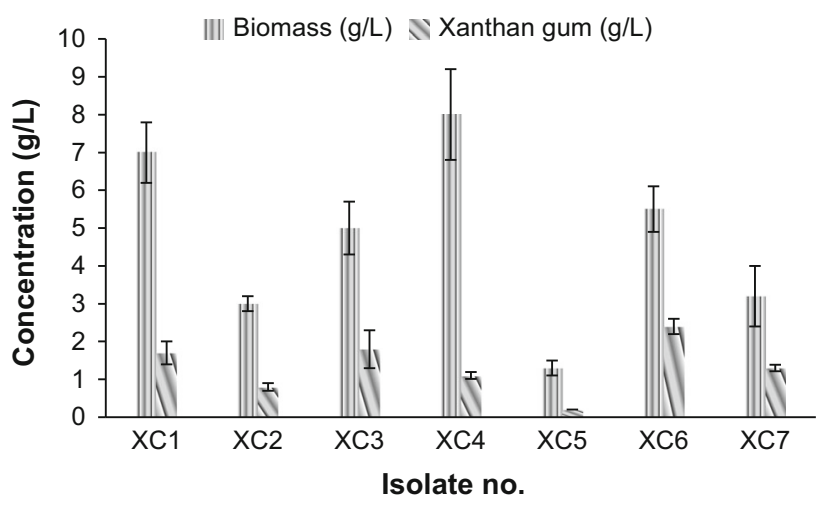

Fig. 1 Xanthan gum production by different isolated bacterial strains

rRNA sequence showed maximum homology (99 \%) with Xanthomonas campestris.

Optimization of carbon source

Out of four commercially available carbon source used for xanthan gum production, maltose proved best carbon source for xanthan gum (6.8 g/L) production (Fig. 2). In glucose, Xanthomonas showed good biomass production as compared to maltose but xanthan gum production $(5.7 \mathrm{~g} / \mathrm{L})$ was low (Fig. 2). Xanthan gum production increased with biomass production and the optimum time for maximum xanthan gum was recorded as $72 \mathrm{~h}$ in maltose as carbon source. Starch is the second most abundantly available carbon source and can be scarified into maltose using bacterial fermentation. Bacillus sp. and Xanthomonas sp. were used separately for the saccharification of potato starch extract to release the reducing sugar. Bacillus sp. released $30.2 \mathrm{~g} / \mathrm{L}$ reducing sugar in $48 \mathrm{~h}$ while Xanthomonas sp. released $14.5 \mathrm{~g} / \mathrm{L}$ after $72 \mathrm{~h}$.

Nitrogen source and temperature

Xanthomonas sp. yields $10.0 \mathrm{~g} / \mathrm{L}$ xanthan gum in $72 \mathrm{~h}$ when yeast extract is used as nitrogen source (Figure S2). Peptone also showed good xanthan gum production, but less in comparison to yeast extract. Beef extract and malt extract act as poor nitrogen source. With the increase of temperature increase in xanthan gum production $(14.7 \mathrm{~g} / \mathrm{L})$ was recorded up to $30{ }^{\circ} \mathrm{C}$ (Fig. 3). At $1 \mathrm{~L}$ scale, xanthan gum production and reducing sugar profile were studied, and $90 \%$ reduction in sugar content was recorded at $72 \mathrm{~h}$ (Fig. 4) in stepwise fermentation. In SSF process, reducing sugar and xanthan gum production go on simultaneously, and maximum reducing sugar of about $14.5 \mathrm{~g} / \mathrm{L}$ is released in $72 \mathrm{~h}$. SSF at $1 \mathrm{~L}$ scale can yield only $6.2 \mathrm{~g} / \mathrm{L}$ xanthan gum, while stepwise approach under optimized condition result in $17.4 \mathrm{~g} / \mathrm{L}$ xanthan gum (Fig. 4). 


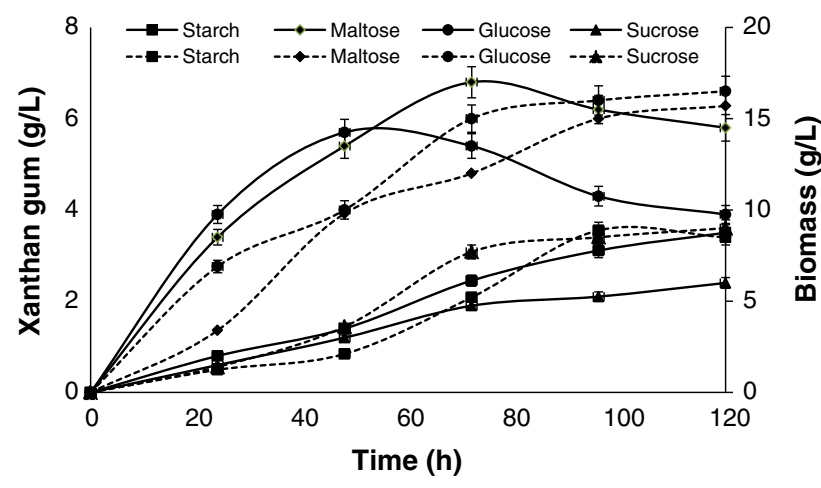

Fig. 2 Xanthan gum production and growth profile of Xanthomonas sp. XC6 on different carbon source

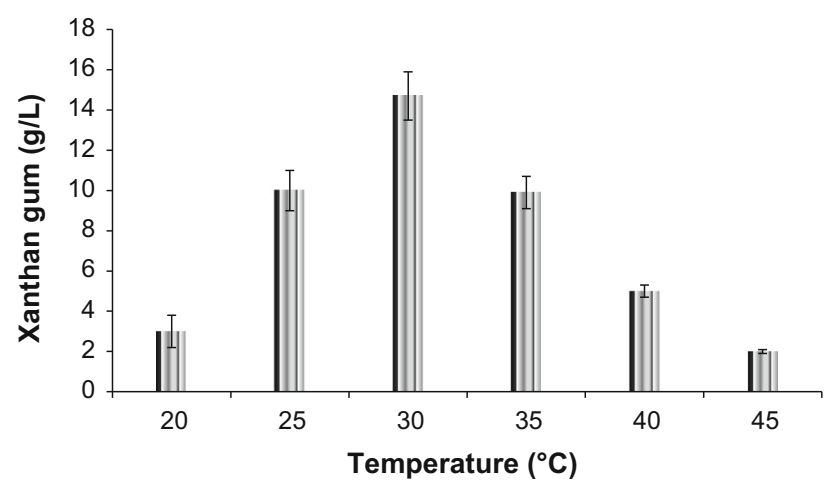

Fig. 3 Effect of temperature on xanthan gum production by Xanthomonas sp. XC6

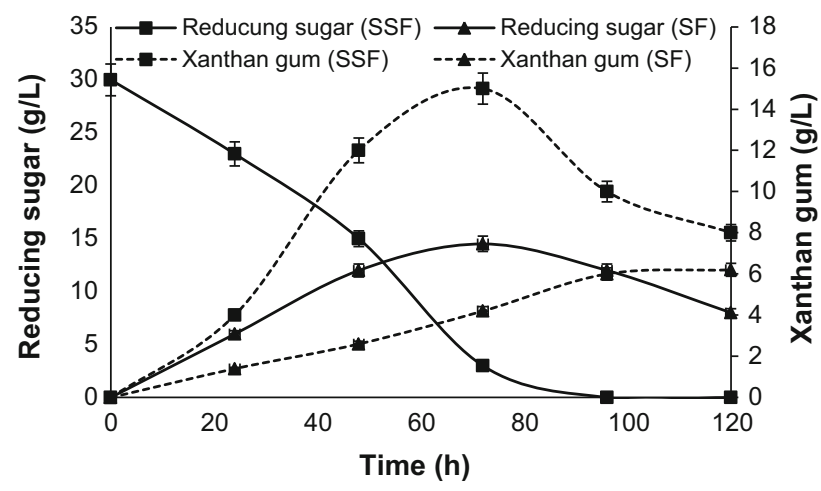

Fig. 4 Xanthan gum production and reducing sugar profile during stepwise and simultaneous saccharification and fermentation

\section{FTIR analysis}

Fourier-transformed infrared spectroscopy of the xanthan gum produced from the Xanthomonas sp. using stepwise fermentation processes was performed. The $x$-axis represents wavelength $\left(\mathrm{cm}^{-1}\right)$ and $y$-axis shows the light transmittance through the sample. Many functional groups were observed: a stretch around $3,464 \mathrm{~cm}^{-1}$ shows the presence of -OH group, peak between 2,880 and $2,967 \mathrm{~cm}^{-1}$ represents $-\mathrm{CH}$ stretching of methyl groups, peak at 1,746 represents the stretching of $-\mathrm{C}=\mathrm{O}$ group, strong signals at 1,746 show the presence of $-\mathrm{C}=\mathrm{O}$ stretching of the acetate group, and a peak at 1,455 shows the presence of $-\mathrm{COOH}$ group.

\section{Discussion}

Xanthan gum is the most commercially produced industrial gum, obtained by fermentation. Development of high-performance xanthan gum-producing microorganisms, reduction of the costs of raw materials, and improvement of fermentation processes are the different approaches that can be used to make production process effective. In this study, xanthan gum-producing bacterial culture Xanthomonas sp. XC6 was isolated from citrus plants having canker disease symptoms and further used for xanthan gum production using starch as substrate. This work showed the importance of the stepwise process for xanthan gum production, as starch is a cheap carbon source and saccharification using amylase activity of Bacillus sp. resulted in fermentation broth with higher sugar content. Bacillus sp. released $30.2 \mathrm{~g} / \mathrm{L}$ reducing sugar in $48 \mathrm{~h}$ while Xanthomonas sp. XC6 released $14.5 \mathrm{~g} / \mathrm{L}$ after $72 \mathrm{~h}$. So a stepwise process, saccharification of potato starch with Bacillus sp. and xanthan gum production using Xanthomonas sp,. was used. Previously, different research group has reported the production of xanthan gum using different materials (whey, molasses, and cassava starch) as carbon source (Kerdsup et al. 2011; Mudoi et al. 2013; Oliveira et al. 2013; Silva et al. 2009). Nitrogen source has an important role in biomass production as well as xanthan gum production. Yeast extract acts as a best nitrogen source for xanthan gum production for Xanthomonas sp. XC6 as already reported for xanthan gum production by Xanthomonas campestries (Gilbert et al. 2013). Temperature also plays a critical role in xanthan gum production, and $30{ }^{\circ} \mathrm{C}$ is the optimum temperature for maximum xanthan gum production in Xanthomonas sp. XC6. The influence of temperature on xanthan gum production has been widely studied by different research groups and found that $28{ }^{\circ} \mathrm{C}$ was the optimal temperature for xanthan gum production (Gumus et al. 2010; Kerdsup et al. 2011; Silva et al. 2009). Under the optimized cultural condition, single step process (SSF) at $1 \mathrm{~L}$ scale can yield $6.2 \mathrm{~g} / \mathrm{L}$ xanthan gum. Xanthan gum production with a stepwise approach at $1 \mathrm{~L}$ scale, under optimized conditions, resulted in $17.4 \mathrm{~g} / \mathrm{L}$, while $5.97 \mathrm{~g} / \mathrm{L}$ xanthan gum production was reported in Xanthomonas campestris TISTR 840 using cassava starch as carbon source (Silva et al. 2009). Fermentation using 
Xanthomonas campestris on waste residual molasses produces only $12.23 \mathrm{~g} / \mathrm{L}$ xanthan gum (Murugesan et al. 2012). Fourier-transformed infrared spectroscopy of xanthan gum, extracted after stepwise process, was performed and it gives the same type of FTIR spectra, as obtained for xanthan gum produced from Xanthomonas campestris using waste residual molasses (Mudoi et al. 2013).

The potentiality of this stepwise approach for xanthan gum production from starch using Xanthomonas sp. XC6 seems to be advantageous over single step process (SSF). Stepwise bioprocess resulted in a $64.36 \%$ increase in xanthan gum production as compared to single step approach under optimized condition.

Acknowledgments The authors gratefully acknowledge the Department of Biotechnology, Indian Institute of Education, Shimla171,011 (H.P) for providing all the facilities for laboratory work.

Conflict of interest The authors declare that they have no conflict of interest in the publication.

Open Access This article is distributed under the terms of the Creative Commons Attribution License which permits any use, distribution, and reproduction in any medium, provided the original author(s) and the source are credited.

\section{References}

Fanga Y, Ahmed S, Liua S, Wanga S, Lua M, Jiaoa Y (2013) Optimization of antioxidant exopolysaccharidess production by Bacillus licheniformis in solid state fermentation. Carbohydr Polym 98:1377-1382

Freitas F, Alves VD, Reis MAM (2011) Advances in bacterial exopolysaccharides: from production to biotechnological applications. Trends Biotechnol 29(8):388-398

Ghazal SMA, Elsayed WS, Badr UM, Gebreel HM, Khali KMA (2011) Genetically modified strains of Xanthomonas campestris higher xanthan producer and capable to utilize whey. Curr Res Bacteriol 4:44-62

Gilani SL, Najafpou GD, Heydarzadeh HD, Zare H (2011) Kinetic models for xanthan gum production using Xanthomonas campestris from molasses. Chem Ind Chem Eng 17(2):179-187

Gilbert L, Loisel V, Savary G, Grisel M, Picard C (2013) Stretching properties of xanthan, carob, modified guar and celluloses in cosmetic emulsions. Carbohydr Polym 93(2):644-650

Gong Y, Wang C, Lai RC, Su K, Zhang F, Wang D (2009) An improved injectable polysaccharide hydrogel: modified gellan gum for long-term cartilage regeneration in vitro. J Mater Chem 19:1968-1977

Gumus T, Demirci AS, Mirik M, Arici M, Aysan Y (2010) Xanthan gum production of Xanthomonas spp. isolated from different plants. Food Sci Biotechnol 19(1):201-206

Kerdsup P, Tantratian S, Sanguandeekul R, Imjongjirak C (2011) Xanthan production by mutant strain of Xanthomonas campestris TISTR 840 in raw cassava starch medium. Food Bioprocess Technol 4:1459-1462

Meng F, Zhou B, Lin R, Jia L, Liu X, Deng P, Fan K, Wang G, Wang L, Zhang J (2010) Extraction optimization and in vivo antioxidant activities of exopolysaccharide by Morchella esculenta SO-01. Bioresour Technol 101(12):4564-4569

Mudoi P, Bharali P, Konwar BK (2013) Study on the Effect of pH, Temperature and aeration on the cellular growth and xanthan production by Xanthomonas campestris using waste residual molasses. J Bioprocess Biotech 3:3

Murugesan AG, Dhevahi B, Gowdhaman D, Bala AK, Sathesh PC (2012) Production of xanthan employing Xanthomonas campestris using sugarcane molasses. Am J Environ Eng 2(2):31-34

Nwodo UU, Green E, Okoh AI (2012) Bacterial Exopolysaccharides: functionality and Prospects. Int J Mol Sci 13:14002-14015

Oliveira PD, Michel RC, McBride AJA, Moreira AS, Lomba RFT, Vendruscolo CT (2013) Concentration regimes of biopolymers xanthan, tara, and clairana, comparing dynamic light scattering and distribution of relaxation time. PLoS One 8:e62713

Patel P, Prajapati JB (2013) Food and health applications of exopolysaccharides produced by lactic acid bacteria. Adv Dairy Res 1:2

Patel SKS, Singh M, Kumar P, Purohit HJ, Kalia VC (2012) Exploitation of defined bacterial cultures for production of hydrogen and polyhydroxybutyrate from pea-shells. Biomass Bioenerg 36:218-225

Rajesh T, Kim YH, Choi YK, Jeon JM, Kim HJ, Park SH, Park HY, Choi KY, Kim H, Kim HJ, Lee SH, Yang YH (2013) Identification and functional characterization of an $\alpha$-amylase with broad temperature and $\mathrm{pH}$ stability from Paenibacillus sp. Appl Biochem Biotechnol 170:359-369

Sangkharak K, Prasertsan P (2013) The Production of Polyhydroxyalkanoate by Bacillus licheniformis using sequential mutagenesis and optimization. Biotechnol Bioprocess Eng 18:272-279

Sayyed RZ, Jamadar DD, Patel PR (2012) Production of Exopolysaccharide by Rhizobium sp. Indian $\mathrm{J}$ Microbiol 51(3):294-300

Silva MF, Fornari RCG, Mazutti MA, Oliveira D, Padilha FF, Cichoski AJC, Cansian RL, Luccio MD, Treichel H (2009) Production and characterization of xantham gum by Xanthomonas campestris using cheese whey as sole carbon source. J Food Eng 90:119-123

Zhang Z, Chen H (2010) Fermentation performance and structure characteristics of xanthan produced by Xanthomonas campestris with a glucose/xylose mixture. Appl Biochem Biotechnol 160:1653-1663 